\title{
NOVO CÒDIGO FLORESTAL VISANDO A PRESERVAÇÃO DOS RECURSOS HÍDRICOS EM UMA MICROBACIA HIDROGRÁFICA.
}

Nome do Autor (a) Principal

Amanda Aparecida de Lima.

Nome (s) do Coautor (a) (s)

Andressa Oliveira Matos; Nathália Janjácomo da Mota.

Nome (s) do Orientador (a) (s)

Yara Manfrin Garcia.

Instituição ou Empresa

Universidade Estadual Paulista “Julio de Mesquita Filho" - UNESP/FCA, Botucatu.

E-mail de contato

aalima2603@gmail.com

Palavras-chave

Sistemas de Informação Geográfica.Área de Preservação Permanente.Microbacia Hidrográfica.

\section{INTRODUÇÃO}

Os desequilíbrios ambientais estão cada vez mais presentes e também deforma mais drástica. É com o exemplo da escassez de água que tomamos partido ao incentivo de estudosrelacionados à conservação e preservação de "agentes cuidadores" dos recursos hídricos. 
Uma forma de manter a preservação e conservação dos recursos hídricos é por meio dasÁreas de Preservação Permanente (APPs). Esse termo foi estabelecido através da Lei no 4.771 de1965, conhecida como Código Florestal, e que atualmente está disposto na Lei oㅜ 12.651/12 comalterações feitas pela Lei Federal oㅡ $12.727 / 12$.

Essas Áreas de Preservação Permanente tem comofunção ambiental de "preservar os recursos hídricos, a paisagem, a estabilidade geológica, abiodiversidade, o fluxo gênico de fauna e flora, proteger o solo e assegurar o bem estar daspopulações humanas" (BRASIL, 2012).

Desta forma, a referida Lei considera-se preservação permanente - em seu artigo $2^{\circ}$ - as florestas e demais formas de vegetação natural situadaao longo dos rios ou de qualquer curso d'água desde o seu nível mais alto em faixa marginal; ao redor das lagoas, lagos ou reservatórios d'água naturais ou artificiais;nas nascentes, ainda que intermitentes e nos chamados "olhos d'água", qualquer que seja a sua situação topográfica, num raio mínimo de 50 (cinquenta) metros de largura (BRASIL, 2012).

Para uma melhor visualização da metragem das Áreas de Preservação Permanente, apresenta-se a Tabela 1 com os seguintes dados de acordo com a largura a partir do leito regular do curso d'água. E, na Figura 1 estáilustrado o exposto.

Tabela 1: Metragem das Áreas de Preservação Permanente.

\begin{tabular}{c|c}
\hline Largura (Rios ou Córregos) & Faixa de Preservação \\
\hline Até 10 metros & 30 m em cada margem \\
\hline Entre 10 e 50 metros & 50 m em cada margem \\
\hline Entre 50 e 200 metros & 100 m em cada margem \\
\hline Entre 200 e 600 metros & 200 m em cada margem \\
\hline Superior a 600 metros & 500 m de cada margem \\
\hline Nascentes & 50 m no entorno da nascente \\
\hline
\end{tabular}

Fonte: BRASIL (2012) apud Garcia (2014) 
Figura 1: Áreas de Preservação Permanente segundo o Código Florestal.

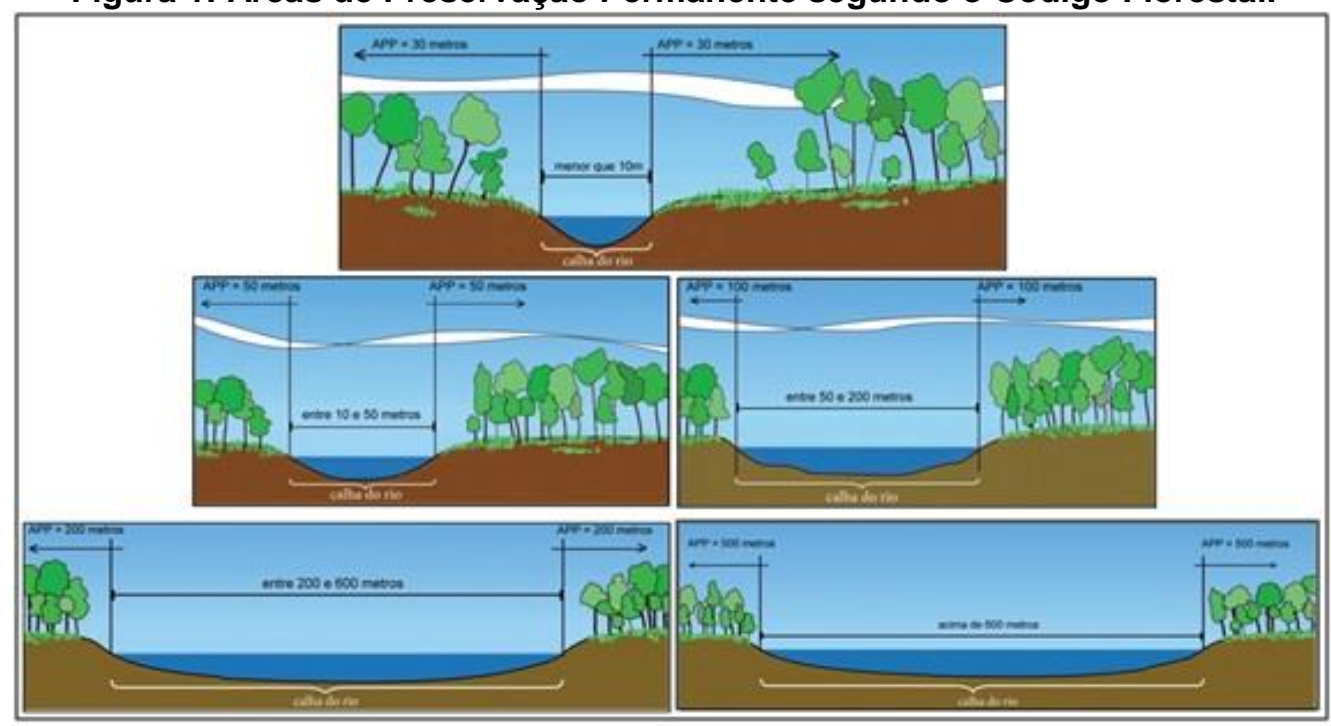

Fonte: Kuntschik (2011). Org.: Autora.

Além da definição apresentada de APPs hídricas, outras áreas também são consideradas ainda em seu art. $2^{\circ}$.

Tomando as APPs no meio rural, Skorupa (2003) ressalta a importância fundamental para o alcance do conceito de desenvolvimento sustentável. Desta forma, é relevante analisar a importância da vegetação nas APPs sob dois aspectos distintos: Importância Física e Serviços Ecológicos, conforme o Quadro 1.

\section{Quadro 1: Importância Física e Serviços Ecológicos das APPs}

\begin{tabular}{|c|l|}
\hline \multirow{1}{*}{$\begin{array}{c}\text { a. Em encostas acentuadas, a vegetação faz com que diminua o risco de erosão, e } \\
\text { protege as áreas mais baixas juntamente com os cursos d'agua; } \\
\text { b. Na área agrícola, pode diminuir, ou até mesmo evitar os processos de erosão do } \\
\text { solo; } \\
\text { c. Atua como quebra-vento em plantaçães; } \\
\text { d. Em regiões onde se encontram nascente, ela funciona como uma ferramenta que } \\
\text { amortece o impacto que a chuva impõe, diminuindo a compactação do solo. Faz com } \\
\text { que o solo permaneça poroso, facilitando a entrada de água que alimenta os lençóis } \\
\text { freáticos, além de auxiliar na diminuição do escoamento superficial da água que pode } \\
\text { estar transportando resíduos prejudiciais ao meio; } \\
\text { e. Nas margens de cursos d'agua, a vegetação impede que o solo que se encontra } \\
\text { naquele local, não escoa para dentro do curso, evitando o seu assoreamento. O autor } \\
\text { descreve essa ação protetora, como "sistema tampão", sistema que evita a entrada de } \\
\text { solo, e/ou água contendo nutrientes e produtos químicos resultantes da ação agrícola; } \\
\text { No controle hidrológico, atua como reguladora do fluxo de água, sendo ela superficial } \\
\text { e subsuperficial, sendo assim, reguladora do lençol freático. }\end{array}$} \\
\hline Serviços & $\begin{array}{l}\text { a. Nesse caso, o autor descreve uma área que é de refúgio para pragas agrícolas, } \\
\text { como sendo sítios para esses inimigos naturais, ou seja, proteção das culturas; } \\
\text { b. Fornecimento de refúgio para agentes polinizadores de culturas; } \\
\text { c. Fornecimento de refúgio para a fauna; } \\
\text { d. Corredores ecológicos que realizam a interconexão entre fragmentos de } \\
\text { vegetação (APP e Reserva Legal), a fim de promover a variância gênica entre a os }\end{array}$ \\
\hline
\end{tabular}




\begin{tabular}{|l|l|}
\hline & indivíduos; \\
e. Controle de pragas do solo; \\
f. Reciclagem de nutrientes; \\
g. Fixação carbono e outros elementos.
\end{tabular}

Fonte: Skorupa (2003)

\section{OBJETIVO GERAL}

O presente trabalho teve como objetivo geral levantar dados com a finalidade de gerarembasamento para adequação das Áreas de Preservação Permanente na microbacia do córrego doKaramacy, Itapeva (SP).

\section{Objetivos Específicos}

Realizarlevantamentos dessas áreas visando novos estudos relacionados às pesquisas de cunho ambiental, especialmente àquelas depreservação e conservação dos recursos hídricos e com base na legislação ambiental vigente.

\section{METODOLOGIA}

O estudo foi conduzido na microbacia do Córrego do Karamaci localizada no municípiode Itapeva-SP, entre as coordenadas geográficas 23⒌'13.81" a 235' 33.98"de latitude S e4853'44.12" a 4850'58.24" de longitude WGr.

A base cartográfica utilizada foi a carta planialtimétrica em formato digital, editada pelo Instituto Brasileiro de Geografia e Estatística - IBGE (1973) referente a folha de Itapeva (SF-22-Z-D-V- 3) em escala 1:50.000.

Para o processamento das informações, georreferenciamento, conversão dos dados vetoriais para raster e, enfim, gerar os buffers de APPs, foi utilizado o Sistema de Informações Geográficas - IDRISI Selva e o software CartaLinx, desenvolvido pela Clark University. O termo buffer é definido para Teixeira e Christofoletti (1997) em ambiente SIG, como uma forma de análise de proximidade onde zonas de uma determinada dimensão são delimitadas em volta de uma feição ou de um elemento geográfico, levando-se em conta um determinado atributo.

As Áreas de Preservação Permanente, de acordo com a legislação vigente, foi considerada30 metros para os cursos d'água já que estes não passam de 10 metros e nas nascentes, um raio mínimo de 50 metros de largura. 


\section{RESULTADOS}

A Figura 2 tem como objetivo apresentar o curso d'água e as nascentes do córrego do Karamacy.Posteriormente, foram gerados os buffers das Áreas de Preservação Permanente da microbacia do córrego do Karamacy. Esse mapa indica a quantidade esperada - e de acordo com a legislação - de mata ciliar para a presente área.

Figura2: Drenagem da microbacia do córrego do Karamacy (A) e Delimitação das APPs
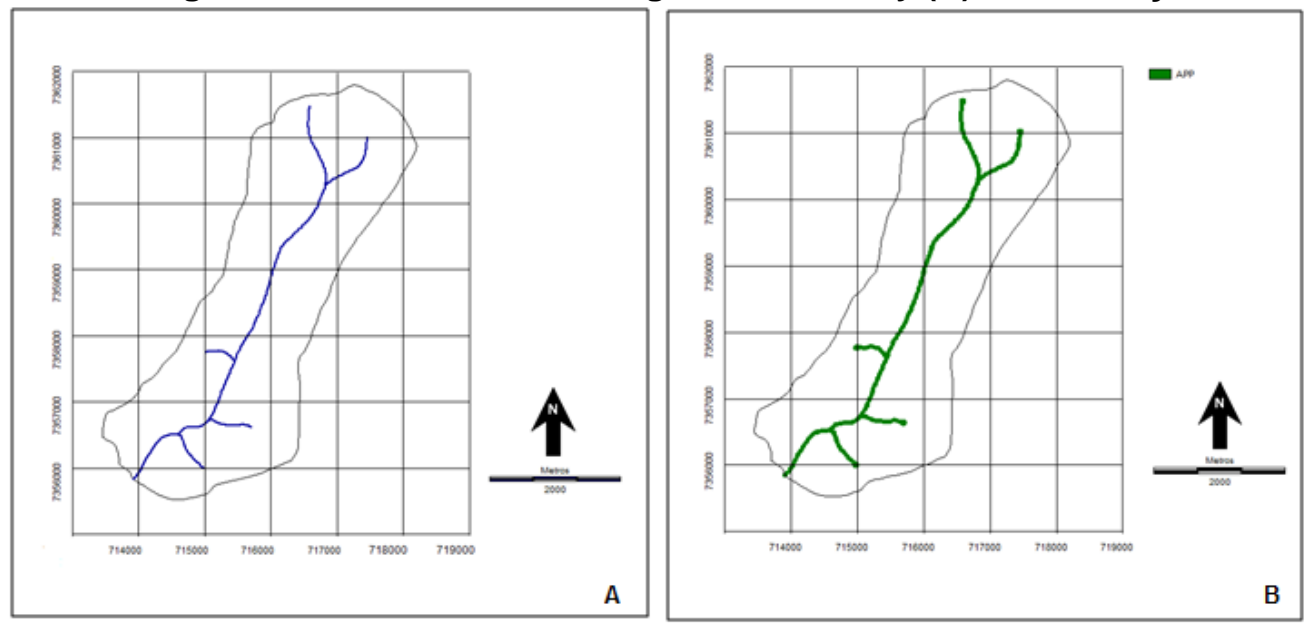

Essas Áreas de Preservação Permanente totalizaram em 66,45 ha de mata ciliar. Vale ressaltar que isso representa $5,15 \%$ em relação a toda área da microbacia que é de $1.289,51$ ha.Não sendo o objetivo deste trabalho, porém, enfatizaremos que 11,67ha de APPs estão em conflitos de uso, ou seja, estão sendo ocupadas por alguma atividade.

Destaca-se novamente que "essas Áreas de Preservação Permanente devem ter a vegetação mantida sem qualquer tipo de alteração, com o objetivo de preservação dos recursos hídricos, estabilidade geológica e da biodiversidade, sem deixar de lado a importância socioambiental" (GARCIA, 2011).

\section{CONCLUSÃO}

O levantamentodas Áreas de Preservação Permanente são de fundamental incentivo a novos estudos que geram subsídios para o principal ação que é a 
conservação e preservação dos recursos hídricos, ambos caminhando dentro da Lei № 12.727/12 e o uso da geotecnologia - Sistema de Informação Geográfica - ajuda no mapeamento preciso da área e serve de suporte para planejamentos futuros na microbacia do córrego do Karamacy e seu entorno.

\section{REFERÊNCIAS}

BRASIL. Lei n o 12.727, de 17 de outubro de 2012. Diário Oficial da União, Brasília, DF, 18 out. 2012. 2012. Disponível em:

< http://www.planalto.gov.br/ccivil_03/_Ato2011-2014/2012/Lei/L12727.htm> Acesso em: 23 out. 2014.

FIGUEIREDO, D. Conceitos Básicos de Sensoriamento Remoto. Companhia Nacional de Abastecimento - CONAB. Brasília - DF. 2005. Disponível em:

<http://www.conab.gov.br/conabweb/download/SIGABRASIL/manuais/conceitos_sm. pdf>. Acesso em: 10 out. 2014.

GARCIA, Y. M. Conflitos de uso do solo em APPs na bacia hidrográfica do córrego Barra Seca (Pederneiras/SP) em função da legislação ambiental. Dissertação (Mestrado em Agronomia) Faculdade de Ciências Agronômicas, Universidade Estadual Paulista, Botucatu, 2014.

GARCIA, Y. M. Aplicação do Código Florestal como subsídio para p Planejamento Ambiental na Bacia Hidrográfica do Córrego do Palmitalzinho - Regente Feijó / São Paulo. Monografia UNESP, Presidente Prudente, SP, 142 p., 2011.

GIANUCA, K. S.; TAGLIANI, C. R. Análise em um Sistema de Informação Geográfica (SIG) das alterações na paisagem em ambientes adjacentes a plantios de pínus no Distrito do Estreito, município de São José do Norte, Brasil. Revista da Gestão Costeira Integrada, 12 (1):43-55, 2012.

KUNTSCHIK, D. P.; EDUARTE, M.; UEHARA, T. H. K. Matas Ciliares. Secretaria do Meio Ambiente - SMA, 1.ed. atualizada, 2011, São Paulo, 84p.

SKORUPA, L. A. Áreas de Preservação Permanente e Desenvolvimento Sustentável. EMBRAPA Meio Ambiente. Jaguariúna, 4p. 2003.

TEIXEIRA, A. L. A.; CHRISTOFOLETTI, A. Sistema de Informações Geográficas: Dicionário ilustrado. São Paulo: Editora Hucitec, 1997. 